\title{
3D model related to the publication: The endocranial anatomy of the stem turtle Naomichelys speciosa from the Early Cretaceous of North America
}

\author{
Paulina-Carabajal Ariana ${ }^{1 *}$, Sterli Juliana ${ }^{2}$, Werneburg Ingmar ${ }^{3,4}$ \\ ${ }^{1}$ INIBIOMA, Universidad Nacional del Comahue, CONICET, Quintral 1250, San Carlos de Bariloche (8400), Argentina \\ ${ }^{2}$ CONICET-Museo Paleontológico Egidio Feruglio, Av. Fontana 140, 9100 Trelew, Argentina \\ ${ }^{3}$ Senckenberg Centre for Human Evolution and Palaeoenvironment (HEP) an der Eberhard Karls Universität, Sigwartstraße 10, 72076 Tübingen, \\ Germany \\ ${ }^{4}$ Fachbereich Geowissenschaften, Eberhard-Karls-Universität, Hölderlinstraße 12, 72074 Tübingen, Germany \\ *Corresponding author: a.paulinacarabajal@conicet.gov.ar
}

\section{Abstract}

The present 3D Dataset contains the 3D model analyzed in the following publication: Paulina-Carabajal, A., Sterli, J., Werneburg, I., 2019. The endocranial anatomy of the stem turtle Naomichelys speciosa from the Early Cretaceous of North America. Acta Palaeontologica Polonica, https://doi.org/10.4202/app.00606.2019

Keywords: brain endocast, inner ear, micro computed tomography, morphology, Testudinata

Submitted:2019-08-27, published online:2019-09-10. https://doi.org/10.18563/journal.m3.99

\section{Model IDs \\ FMNHPR273 \\ Description \\ skull and endocasts}

Table 1. Naomichelys speciosa skull model from the Field Museum of Natural History, Chicago, USA

\section{INTRODUCTION}

Helochelydrids belong to stem Testudines and were present in North America and in Europe since the Tithonian and up to the Maastrichtian. Naomichelys speciosa HAY 1908 is the only known helochelydrid species present in North America, and it has been recognized in different localities ranging from the Aptian to the Campanian (Joyce et al. 2011). Its skeletal anatomy has been studied by Joyce et al. (2014) and Lautenschlager et al. (2018). The endocasts of the brain, cranial nerves and blood vessels, and the inner ear have been reconstructed and described in detail based on $\mu$ CT-data (see Table 1 and Fig. 1) (Paulina-Carabajal et al. 2019). N. speciosa was a terrestrial turtle characterized by a large olfactory region suggesting that olfaction was an important sense of this species.

\section{METHODS}

The 3D surfaces were extracted semi-automatically within MIMICS 18.0 using the segmentation threshold selection tool. The 3D surface models are provided in .ply format, and can therefore be opened with a wide range of freeware.

\section{ACKNOWLEDGEMENTS}

Grant sponsors: 1. Agencia Nacional de Promoción Científica y Tecnológica, 2. Swiss National Science Foundation, 3. Deutsche Forschungsgemeinschaft. Grant numbers: 1. PICT-2016-0481 to AP-C, 2. P300PA_164720 to IW, 3. WE 5440/6-1 to IW.

\section{BIBLIOGRAPHY}

Hay, O.P., 1908. The Fossil Turtles of North America. Carnegie Institution of Washington, No 75, $810 \mathrm{p}$.

Joyce, W.G., Chapman, S.D., Moody, R.T. and Walker, C.A., 2011. The skull of the solemydid turtle Helochelydra nopcsai from the Early Cretaceous of the Isle of Wight (UK) and a review of Solemydidae. Special Papers in Palaeontology 86, 75-97.

Joyce, W.G., Sterli, J. and Chapman, S.D., 2014. The skeletal morphology of the solemydid turtle Naomichelys speciosa from the Early Cretaceous of Texas. Journal of Paleontology 88, 1257-1287. https://doi.org/10.1666/14-002

Lautenschlager, S., Ferreira, G.S., and Werneburg, I., 2018. Sensory evolution and ecology of early turtles revealed by digital endocranial reconstructions. Frontiers in Ecology and Evolution 6, https://doi.org/10.3389/fevo.2018.00007

Paulina-Carabajal, A., Sterli, J., Werneburg, I., 2019. The endocranial morphology of the stem turtle Naomichelys speciosa from the Early Cretaceous of North America. Acta Palaeontologica Polonica, https://doi.org/10.4202/app.00606.2019 
A)

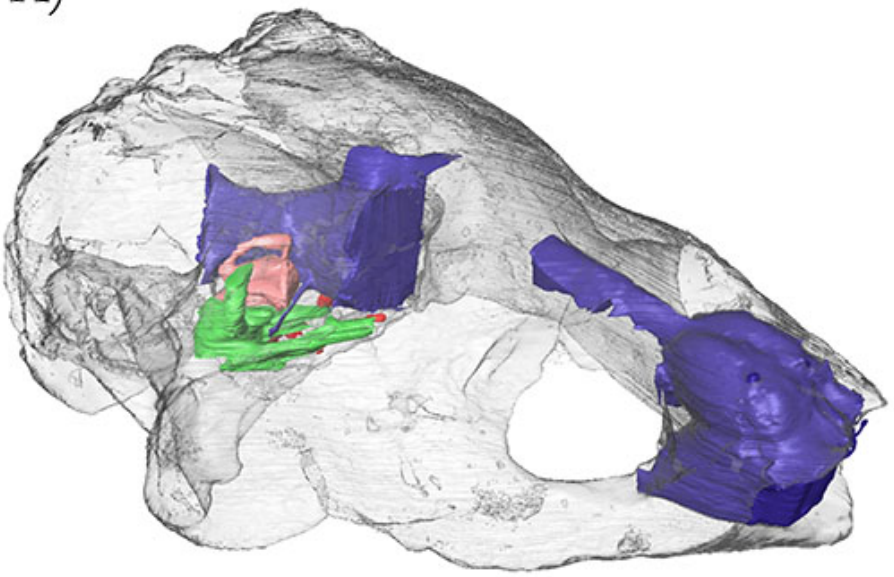

C)

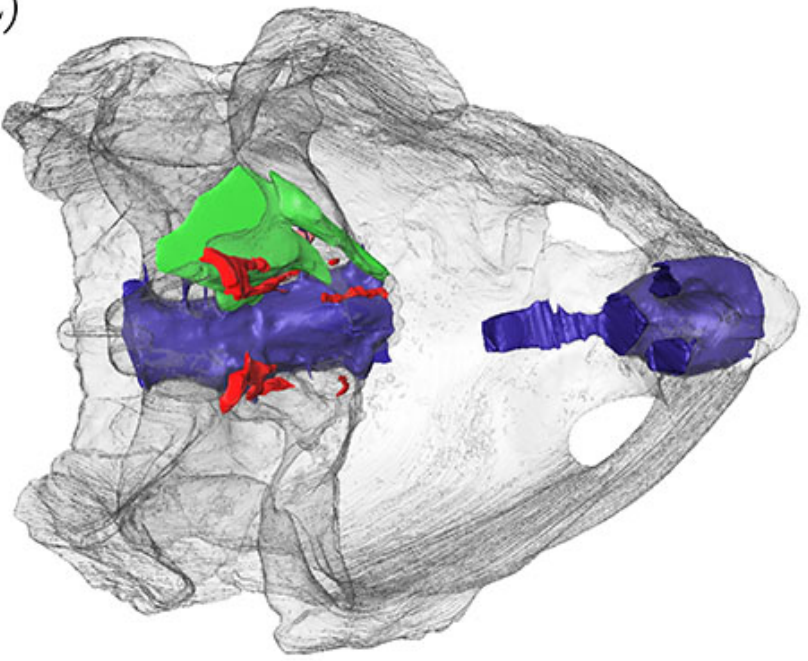

E)

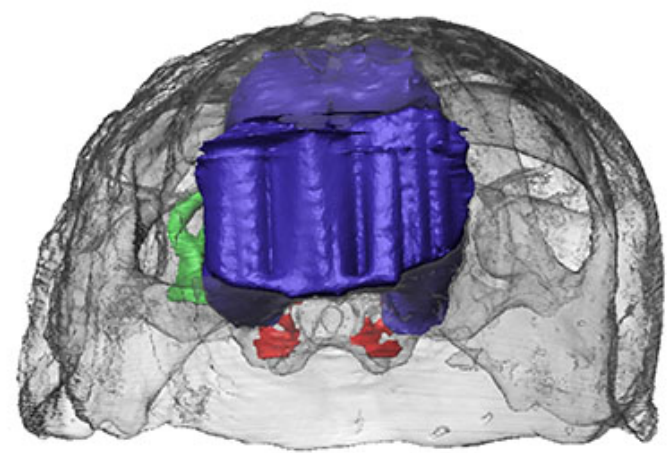

B)

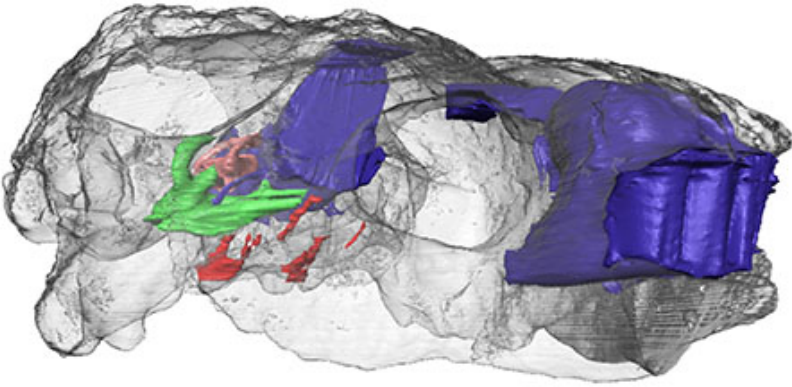

D)

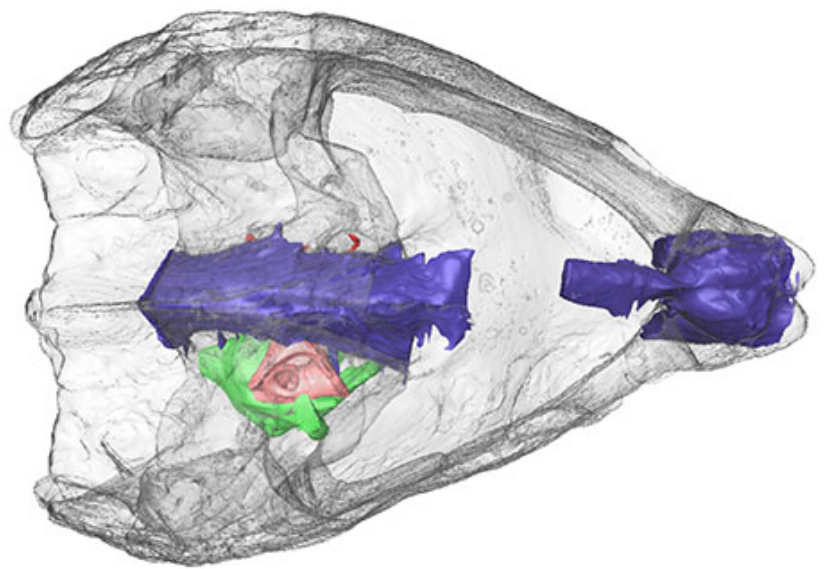

F)

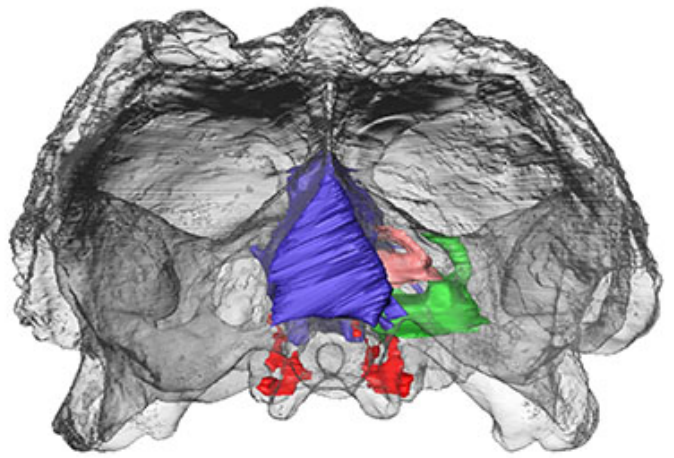

Figure 1. Skull and endocasts of the stem turtle Naomichelys speciosa (FMNH PR273; Field Museum of Natural History, Chicago, USA) in A) oblique anterodorsal, B) anterolateral, C) ventral, D) dorsal, E) anterior, and F) posterior view. Skull transparent. Blue, endocast of the brain, cranial nerves, and nasal cavity; red, blood vessel endocasts; green, endocast of the cavum acustico-jugulare; pink, cast of inner ear; yellow. Skull length: $129 \mathrm{~mm}$. 